\title{
Spor Bilimlerinde Okuyan Öğrencilerin Zaman Yönetimi Davranışları
}

\author{
Bereket KÖSE* $\quad$ Meliha UZUN DÖNMEZ**
}

\begin{abstract}
Özet
$\mathrm{Bu}$ çalışma, Ankara Üniversitesi spor bilimlerinde okuyan öğrencilerin zaman yönetimi davranışlarının incelenmesi amacıyla yapılmıştır. Araştırmayı, Ankara Üniversitesi Spor Bilimleri Fakültesinde okuyan 171'i kadın, 179'u erkek olmak üzere toplam 350 öğrenci oluşturmaktadır. Araştırmada veri toplama aracı olarak; "Demografik Bilgi Formu" ile Britton ve Tesser (1991) tarafından geliştirilen, Alay ve Koçak (2002) tarafından Türkçe'ye uyarlanan "Zaman Yönetimi Envanteri” kullanılmıştır. Verilerin dağılımlarının normal olup olmadığının belirlenmesinde Kolmogorov- Smirnov testi kullanılmıştır. Veriler normal dağılım sağladığı için parametrik testler uygulanmıştır. Verilerin değerlendirilmesi aşamasında; "Bağımsız t-testi, Anova analizi ve Tukey çoklu karşılaştırma testleri kullanılmıştır. Analiz sonucunda cinsiyet değişkenine göre; zaman harcattırıcılar alt boyutu ile genel zaman yönetimi puanında istatistiksel olarak anlamlı bir fark saptanmıştır $(p<0,05)$. Katılımcılar okudukları bölüme ve okul başarı not ortalamalarına göre incelendiğinde; alt boyutlar ve genel puanda istatistiksel olarak anlamlı bir farkllık tespit edilmemiştir $(\mathrm{p}>0,05)$. Sonuç olarak; spor bilimlerinde öğrenim gören öğrencilerin okudukları bölüm ile okuldaki başarılarının zaman yönetimi durumlarına etki etmediği görülmektedir. Cinsiyet değişkeninin ise zaman yönetiminde bir etken olduğu gözlemlenmektedir. Ankara Üniversitesi Spor Bilimlerinde okuyan öğrencilerin genel olarak zaman yönetimi tutumlarının orta düzeyde olduğu ve zamanı kullanmakta güçlük çektikleri görülmektedir. Zamanı daha verimli kullanabilmek için zaman yönetimi kavramının öneminin vurgulanması gerekmektedir.
\end{abstract}

Anahtar Kelimeler: Öğrenci, Spor, Zaman Yönetimi

\section{Time Management Behaviors of the Students who Study in Sports Sciences}

\begin{abstract}
This study aimed to investigate time management behaviors of the students studying at Ankara University Faculty of Sport Sciences. Totally 350 students (171 females, 179 males) voluntarily participated in this study. "Demographic Information Form" and "Time Management Questionnaire" developed by Britton and Tesser (1991) and adapted into Turkish by Alay and Koçak (2002) were used as data collection tools. The normality of the data was tested with Kolmogorov- Smirnov test. As the data were normally distributed, parametric tests were used. Independent Sample T-test, ANOVA and Tukey Multiple comparison test were used to analyze the data. According to the gender variable, statistically significant difference was observed between Time Wasters subdimension and total score of time managements $(\mathrm{p}<0,05)$. When participants were evaluated according to departments and cumulative grade point average, no significant difference was found between sub-dimensions and total score $(\mathrm{p}>0,05)$. In conclusion, it was inferred that the departments sport sciences students are studying and their cumulative grade point scores did not affect their time management behaviors. Gender variable was observed to be a determinant in time management. It is seen that the students in Ankara University Sports Sciences generally have moderate time management attitudes and have difficulty in using time.

The importance of time management should be highlighted in order for students to use the time more effectively. Keywords: Student, Sport, Time management
\end{abstract}

\section{GíRIŞ}

İçinde yaşadığımız bilgi toplumu aşamasında, hayat her geçen an hızlanmaktadır. İnsanlar özel hayatlarında olduğu gibi çalışma hayatlarında da pek çok işi başarılı bir şekilde gerçekleştirmek için zaman ile

\footnotetext{
*Dr. Öğr. Üyesi, Şırnak Üniversitesi, Beden Eğitimi ve Spor Yüksekokulu, Şırnak-TÜRKİYE, bereket.kose@ hotmail.com **Dr. Öğr. Üyesi, Şırnak Üniversitesi, Beden Eğitimi ve Spor Yüksekokulu, Şırnak-TÜRKIYYE, melihauzunn16@gmail.com
} 
yarışmaktadırlar (Karadağ, 2013). Günümüzde ise özellikle profesyonel çalışma hayatında zamanın yönetimi başarı için en önemli faktörlerden biri olarak belirtilmektedir (Çelik ve Akatay, 2007). Zaman, hızlı bir şekilde akıp giden ve bütün insanların eşit olarak faydalandığ 1 çok önemli değer olarak tanımlanmaktadır (Güven ve Yeşil, 2011). Zaman, bireylerin özel ve meslek yaşantılarında amaçlarına etkili ve verimli bir biçimde hizmet etmesi için ve uzun vadeli başarılı planların yapılabilmesi için iyi şekilde planlanmal1, organize edilmeli, yönlendirilmeli, koordine edilmeli ve kontrol altına alınmalıdır (Erdem ve ark., 2005; Ayyıldız Durhan, 2019). Zaman1 etkili ve planlı bir biçimde kullanmak isteyen bireylerin temelde yapması gereken en önemli şey plan içerisinde programlamanın iyi yapılmasıdır. $\mathrm{Bu}$ bağlamda insanlığa lütuf edilen zaman olgusunu nicelik ve nitelik olarak yaşamın içerisinde en iyi biçimde kullanılabilmesi çalışma yaşamına, toplumsal yaşamına, dinlenme ve eğlencesine, beşeri ihtiyaçlarının karşılanmasına ayıracağı zamanın dengesini iyi kurabilmesine bağlıdır (Köktaş ve Köktaş, 2007). Özellikle tüm insanlar zaman miktarını kullanabilme bakımından aynı hakka sahiptir. Çoğu insan zamanın yetersiz olduğundan yakınır; fakat bazı insanlar zamanı etkili bir şekilde değerlendirir ve daha fazla iş yapmayı becerebilirler. $\mathrm{Bu}$ durumun nasıl olabileceğini anlayabilmek en önemli meseledir. Bunun anahtarının zaman yönetimi olduğunu söylemek şüphesiz doğru olacaktır. "Zaman yönetimi, işgücü açısından yoğun bir yaşama sahip yöneticilerin zamanlarını daha iyi organize etmelerine yardımcı olmak için bir eğitim aracı olarak Danimarka'da doğmuş, dünyaya yayılmış" (Çelik ve Akatay, 2007) ve "amaçlara ulaşmada önemli bir kaynak olan zamanı verimli kullanma çabası olarak tanımlanmaktadır (Uğur, 2000). Zaman yönetiminin amacı, yanlış işleri hızlı bir şekilde yapmak değil; kısa zaman içinde doğru işi yapmaktır (Gürbüz ve Aydın, 2012).

Descartes, toplumların ülkelerin gelişmişlik düzeylerinin veya zenginliklerinin anlamlandırırken, zamanı kaynak olarak planlı ve programlı kullanarak çalışmaya veya dinlenmeye yeteri kadar zaman ayırmalarından kaynaklandığını belirtmektedir (Köktaş ve
Köktaş, 2007). Özellikle spor alanında çalışan bireylerin zaman yönetimine ilişkin tutumları önemli bulunmaktadır. Yaşar ve Sunay'a göre (2018) antrenörlerin ve spor içerisinde bulunan bireylerin vizyon sahibi olması ve bu anlamda geleceğini iyi planlaması gerektiği ifade edilmiştir. İleriki yıllarda öğretmen, yönetici ya da antrenör olarak sektöre katkı sağlayacak olan spor bilimleri fakültesi öğrencilerinin diğer özelliklerinin yanında zaman yönetimi davranışı konusundaki eğilimleri büyük önem arz etmektedir.

Dolayısıyla her geçen gün büyük bir hızla değișen ve gelişim gösteren spor sektörünün bu değişim ve büyümeyi istikrarlı bir şekilde sürdürebilmesi spor alanında eğitim görmüş, sporun dinamiklerini ve sporcuyu iyi bilen, sektörün gereksinimlerini tespit edebilecek, spor hizmet ve faaliyetlerinin sevk ve idaresini sağlayabilecek, piyasa eğilimlerini önceden kestirip, buna göre önlem ya da yatırım yapabilecek, modern yönetim ilkelerinin gerekliliklerini yerine getirme kabiliyetine sahip yetişmiş elemanlara bağlıdır (Uyar ve Sunay, 2009). Zaman kavramı ve onun iyi bir şekilde yönetilmesi elzem bir unsurdur. Çünkü yaşamda geri getirilmesi mümkün olmayan tek şeydir. Bireylerin zamanı iyi kullanmas1 başarıyı yakalamalarında büyük bir öneme sahiptir. Bu bağlamda bu çalışmanın amacı, Ankara Üniversitesi Spor Bilimlerinde okuyan öğrencilerinin zaman yönetimi davranışlarının incelenmesidir.

\section{YÖNTEM}

Çalışma, 2017-2018 öğretim yılında Ankara Üniversitesi Spor Bilimleri Fakültesinde okuyan yaş ortalamaları $21,95 \pm 2,61$ olan 171 kadın 179 erkek olmak üzere toplam 350 öğrenci katılmıştır. Gönüllü olan öğrencilerin çalışmaya dahil edilmesi örneklem seçimini belirlemede etkendir. Verilerin toplanmas1 aşamasında Zaman Yönetimi Envanteri ile demografik özellikleri belirlemeye yönelik form kullanılmıştır. ZYE Britton ve Tesser (1991) tarafından geliştirilmiştir. Alay ve Koçak (2002) tarafından Türkçe'ye uyarlaması yapılmıştır. ZYE'de toplam 27 madde vardır. Envanter, "zaman planlaması", "zaman tutumları" ve "zaman harcattırıcılar" olmak üzere 3 alt boyuttan meydana gelmektedir. 
$\checkmark$ Zaman planlamasinda 16 maddeden oluşmaktadır. 16. madde tersine puanlanmaktadir.

$\checkmark$ Zaman tutumları kisminda toplam 7 soru vardır. Bunların 4'ü düz, 3’ü (2, 6 ve 7 . maddeler) ise tersine puanlanmaktadır.

$\checkmark$ Zaman harcattırıcılar kısmında ise 4 soru vardır ve bu soruların tümü tersine puanlanmıştır.

ZYE için yapılan güvenirlilik çalışmasında Cronbach alpha planlama alt boyutu 0,87 ; zaman tutumları 0,84 ; uzun vadeli planlama için 0,89 bulunmuştur. $\alpha$ seviyesi tüm ölçek için ise 0,86 'dır. Veriler SPSS-20 paket programı ile değerlendirilmiştir. Katılımcıların tüm değişkenler için ortalama, standart sapma hesaplamasında tanımlayıcı istatistik yöntemi kullanılmıştır. Verilerin dağılımlarının normal olup olmadığının belirlenmesinde Kolmogorov-Smirnov testi kullanılmıştır. Analiz sonucunda çıkan değerler normallik varsayımını sağladığı için parametrik testler uygulanmıştır. Verilerin değerlendirilmesinde "Bağımsız t-testi ve Anova analizi ile Tukey çoklu karşılaştırma testleri kullanılmıştır.

\section{BULGULAR}

Tablo 1. Katılımcıların cinsiyet faktörüne göre t- testi sonuçları

\begin{tabular}{lcccc}
\hline $\mathrm{n}=350$ & Cinsiyet & Ort \pm SS & t & P \\
\hline Zaman & Kadın & $2,80 \pm 0,67$ & - & \\
& Erkek & $2,92 \pm 0,71$ & 1,664 & 0,97 \\
\hline Zaman & Kadın & $2,71 \pm 0,50$ & - & 0,25 \\
Tutumları & Erkek & $2,77 \pm 0,45$ & 1,148 & \\
\hline Zaman & Kadın & $2,61 \pm 0,59$ & - & \\
Harcattırıcılar & Erkek & $2,87 \pm 0,66$ & 3,771 & $\mathbf{0 , 0 3} *$ \\
\hline Genel Zaman & Kadın & $2,75 \pm 0,48$ & $-2,46$ & $\mathbf{0 , 0 4}$ \\
Yönetimi & Erkek & $2,87 \pm 0,47$ & & \\
\hline *p<0,05 & & & &
\end{tabular}

Tablo 1'de kat1lımciların cinsiyet değişkenine göre analiz sonuçları incelendiğinde zaman harcattırıcılar alt boyutu ile genel zaman yönetimi puanında istatistiksel olarak anlamlı bir fark tespit edilmiştir $(p<0,05)$. Bu farkların erkek ögrenciler lehinde olduğu görülmektedir (Zaman harcattırıcılar ortalama $=$ Erkek: 2,87; Kadın: 2,61), (Genel zaman yönetimi ortalama= Erkek: 2,87; Kadın: $2,75)$.

Tablo 2. Katılımcıların okudukları bölümlere göre Anova sonuçları

\begin{tabular}{llllll}
\hline $\mathrm{n}=350$ & $\begin{array}{l}\text { Zaman } \\
\text { Planlama } \\
\text { Ort } \pm \text { SS }\end{array}$ & $\begin{array}{l}\text { Zaman } \\
\text { Tutumları } \\
\text { Ort } \pm \text { SS }\end{array}$ & $\begin{array}{l}\text { Zaman } \\
\text { Harcattırıcılar } \\
\text { Ort } \pm \text { SS }\end{array}$ & $\begin{array}{l}\text { Genel } \\
\text { Zaman } \\
\text { Yönetimi } \\
\text { Ort } \pm \text { SS }\end{array}$ & p \\
\hline Öğretmenlik & $2,85 \pm 0,70$ & $2,79 \pm 0,44$ & $2,84 \pm 0,69$ & $2,83 \pm 0,49$ & $>0$ \\
\cline { 1 - 4 } Antrenörlük & $2,89 \pm 0,71$ & $2,72 \pm 0,51$ & $2,72 \pm 0,57$ & $2,82 \pm 0,49$ &, 05 \\
\cline { 1 - 3 } Yöneticilik & $2,85 \pm 0,67$ & $2,71 \pm 0,48$ & $2,70 \pm 0,65$ & $2,79 \pm 0,46$ & \\
\hline $\mathrm{p}>0,05$ & & & & &
\end{tabular}

Katılımcılar okudukları bölümlere göre incelendiğinde zaman planlama ile tutumları alt boyutları ve genel zaman yönetimi puanında anlamlı bir fark bulunmamıştır $(\mathrm{p}>0,05)$.

Tablo 3. Katılımcıların okul başarı not ortalamalarına göre Anova sonuçları

\begin{tabular}{|c|c|c|c|c|c|}
\hline$n=350$ & $\begin{array}{c}\text { Zaman } \\
\text { Planlama } \\
\text { Ort } \pm \text { SS }\end{array}$ & $\begin{array}{c}\text { Zaman } \\
\text { Tutumları } \\
\text { Ort } \pm \text { SS }\end{array}$ & $\begin{array}{c}\text { Zaman } \\
\text { Harcattıricilar } \\
\text { Ort } \pm \text { SS }\end{array}$ & $\begin{array}{c}\text { Genel } \\
\text { Zaman } \\
\text { Yönetimi } \\
\text { Ort } \pm \text { SS }\end{array}$ & $\mathbf{p}$ \\
\hline $\begin{array}{l}2,00 \\
\text { ve } \\
\text { alti } \\
\end{array}$ & $3,04 \pm 0,67$ & $2,74 \pm 0,41$ & $2,76 \pm 0,61$ & $2,86 \pm 0,38$ & \multirow{4}{*}{$\mathrm{p}>0,05$} \\
\hline $\begin{array}{l}2,01 \\
\text { ve } \\
2,50\end{array}$ & $2,99 \pm 0,70$ & $2,79 \pm 0,44$ & $2,80 \pm 0,68$ & $2,91 \pm 0,46$ & \\
\hline $\begin{array}{c}3,01 \\
\text { ve } \\
3,50\end{array}$ & $2,98 \pm 0,69$ & $2,77 \pm 0,50$ & $2,79 \pm 0,66$ & $2,87 \pm 0,48$ & \\
\hline $\begin{array}{c}3,51 \\
\text { ve } \\
4,00\end{array}$ & $2,97 \pm 0,58$ & $2,80 \pm 0,48$ & $2,81 \pm 0,61$ & $2,90 \pm 0,88$ & \\
\hline
\end{tabular}

Tablo 3'te okul başarı not ortalamalarına göre; $\quad$ zaman= planlama, tutumları, harcattırıcilar alt boyutları ile genel zaman yönetimi puanında istatistiksel olarak anlamlı bir farkl111k yoktur ( $\mathrm{p}>0.05)$.

\section{TARTIŞMA ve SONUÇ}

Öğrencilerin zaman yönetimi davranışlarının incelendiği bu araştırmada elde edilen bulgular aşağıda yorumlanmıştır.

Tablo 1'de katılımcılar cinsiyet faktörüne göre incelendiğinde tüm alt boyutlara ilişkin puanlar yüksektir fakat istatistiksel olarak "Zaman Harcattırıcilar" ile "Genel Zaman Yönetimi” puanları arasında cinsiyete göre anlamlı farklılık olduğu tespit edilmiştir 
$(\mathrm{p}<0,05)$. Çalışmamızda zaman harcattırıcılarının erkek öğrencilerin lehine olması, zaman tuzaklarına karşı erkeklerin daha dikkatli tutum izlediklerini bize düşündürebilir. Zaman yönetimi envanterinde erkeklerin kadınlara oranla daha fazla ortalamaya sahip olması, erkeklerin toplumda üstlendikleri sorumluluklardan ötürü daha programlı yaşamlarını sürdürmeleri gerektiğinden kaynaklanabilir. Çalışmamızın aksine, Sugötüren ve arkadaşları (2011) yapmış oldukları araştırmada farkın kadın öğrenciler lehinde olduğunu tespit etmişlerdir. Alay ve Koçak (2003) tarafından yapılan bir başka araştırmada, zaman yönetimi davranışlarının kadınlar lehinde olduğunu belirtmişlerdir. Yine, Bay, Tuğluk ve Gençdoğan (2005) araştırmalarında, farkın kadınlar lehinde olduğunu tespit etmişlerdir. Gümüş ve Alay (2017) ise zaman konusunda kadınların erkeklere oranla daha fazla kısıtlama ile karşılaşmalarından ötürü dezavantajlı olduğunu bildirmiştir. İlaveten, Tektaş ve Tektaş (2010), Macan ve arkadaşları (1990), Nelson ve Nelson (2003) yapmış oldukları çalışmada, kız öğrencilerin genel olarak zaman yönetiminde daha iyi durumda olduklarını belirtmişlerdir. Benzer şekilde yapılan diğer araştırmalarda da zaman tuzakları olan zaman harcattırıcılar alt boyutlarında kadınlar lehine farklılık olduğu belirtilmektedir (Caz ve Tunçkol, 2015; Gözel, 2009; Demirtaş ve Özer, 2007; Erdul, 2005; Trueman ve Hartley, 1996; Gümüş, Ayna ve Yildırım, 2018; Misra ve Mckean, 2000). Karaoğlu (2015) ise yaptığı çalışmada zaman yönetimi ve alt boyutlarmin cinsiyet faktöründen etkilenmediğini bildirmiştir. Yine, İşcan (2008), Alay ve Koçak (2002), Andıç (2009) ile Yılmaz ve arkadaşlarının (2010) yaptıkları araştırmalarda anlamlı farklılığın tespit edilmediği gözlemlenmiştir. Y1lmaz ve arkadaşları (2019)gönüllülük faaliyetlerine katılımda zaman boyutunun cinsiyet açısından farklılaşmadığını belirtmişlerdir. Tüm bu çalışmaların bulguları ile çalışma bulguları örtüşmemektedir. Çünkü çalışmanızda erkek ögrenciler lehine bir anlamlı farklılık olduğu bulunmuştur fakat atıf yapan çalışmalar kadınlar lehine anlamlı farklılık bulmuş ya da hiçbir anlamlı farklılık tespit edilememiştir.

Spor Bilimleri Fakültesinde okuyan öğrencileri okudukları bölümlere göre verileri değerlendirildiğinde zaman yönetimi ve diğer alt boyutlarında istatistiksel açıdan anlamlı bir farkl11ık bulunmamıştır (p>0,05). İşcan (2008) yapmış olduğu araştırmada, zaman yönetimi ile öğrencilerin okudukları fakülteye göre değişiklik göstermediğini tespit etmiştir. Yine, Sugötüren ve arkadaşları (2011) tarafından spor bilimlerinde öğrenim gören öğrencilerin bölüme yönelik zaman yönetimi davranışları incelenmiştir. $\mathrm{Bu}$ araştırmaya göre ne alt boyutlarda ne de genel puanda anlamlı bir fark bulunmamıştır.

Tablo 3'te ise katılımcıların okul başarı ortalamalarına göre verileri incelendiğinde hem zaman yönetimi hem de diğer alt boyutlarında istatistiksel olarak anlamlı fark gözlenmemiştir $(p>0,05)$. Tektaş ve Tektaş (2010) araştırmalarında, genel zaman yönetimi ve zaman planlaması alt boyutunda akademik başarıya göre anlamlı bir fark görülmemektedir. Çalışmamızın sonucuyla bu bulgular örtüşmektedir. Yine aynı çalışmada, zaman tutumları ile zaman harcattırıcilar alt boyutlarında akademik başarı ilişkisi açısından anlamlı fark bulunmuştur. Sonuçlarımız bu çalışmanın bulgularıyla zıtlık göstermektedir. Çalışmamızın aksine yapılan diğer çalışmalarda ise zaman tutumlarının akademik başarının bir göstergesi olduğu vurgulanmıştır (Britton ve Tesser, 1991; Alay ve Koçak, 2002). Ancak Mpofu ve arkadaşları (1996) tarafından yapılan çalışmada ise bu yargıyı desteklemeyen bir sonuç ortaya çıkmıştır. Bunun sebebi olarak kültürel farklilıkların etkili olabileceği vurgulanmaktadır. Bununla birlikte tutumların akademik başarının göstergesi olup olmayacağı üstüne bu tarz bir genellemenin yapılabilmesi için başka kültürlerde de benzer araştırmalar yapılmasına ihtiyaç duyulduğunu savunmaktadırlar.

\section{Bulgulara göre;}

$\checkmark$ Cinsiyet değişkenine göre incelendiğinde; zaman harcattırıcılar alt boyutu ile genel zaman yönetimi puanında anlamlı fark tespit edilmiştir. $\mathrm{Bu}$ farkın erkek öğrencilerin lehine olduğu görülmektedir.

$\checkmark$ Öğrencilerin okudukları bölümlere göre zaman yönetimi durumlarına göre; hem genel zaman yönetimi 
puanda hem de diğer alt boyutlarda fark ortaya çıkmamıştır.

$\checkmark$ Okul başarısının etkisi incelendiğinde; alt boyutlarda da, genel zaman yönetimi puanında da anlamlı bir fark oluşmamıştır.

Sonuç olarak, Ankara Üniversitesi Spor Bilimlerinde okuyan öğrencilerin genel olarak zaman yönetimi tutumlarının orta düzeyde olduğu ve zamanı kullanmakta güçlük çektikleri görülmektedir. Zamanı daha verimli kullanabilmek için zaman yönetimi kavramının öneminin vurgulanması gerekmektedir.

\section{KAYNAKÇA}

Alay, S. ve Koçak, S. (2002). Validity and Reliability of Time Management Questionnaire. Hacettepe Üniversitesi Eğitim Fakültesi Dergisi, 22, 9-13.

Alay, S. ve Koçak, S. (2003). Üniversite Öğrencilerinin Zaman Yönetimleri ile Akademik Başarıları Arasındaki İlişki. Kuram ve Uygulamada Eğitim Yönetimi Dergisi, 35, 326-335.

Andıç, H. (2009). Üniversite Öğrencilerinin Zaman Yönetimi Becerileri İle Akademik Başarıları Arasındaki İlişki. Yüksek Lisans Tezi, Afyon Kocatepe Üniversitesi Sosyal Bilimler Enstitüsü, Afyonkarahisar.

Bay, E., Tuğluk M.N. ve Gençdoğan B. (2005). Üniversite Öğrencilerinin Ders Çalışma Becerilerinin İncelenmesi. Elektronik Sosyal Bilimler Dergisi, 4, 94-105.

Britton, B.K. ve Tesser, A. (1991). Effects of Time Management Practices on College Grades. Journal of Educational Psychology, 83(3), 405-410.

Caz, Ç. ve Tunçkol, H.M. (2015). Beden Eğitimi Öğretmenlerinin Zaman Yönetimi Becerilerinin İncelenmesi. Spor ve Performans Araştırmaları Dergisi, 6(2), 91-100.

Çelik, A. ve Akatay, A. (2007). Örgütlerde Zaman Yönetimi, Zaman Yönetimi ve Yönetsel Zamanda Etkinlik. Ankara: Gazi Kitabevi.
Demirtaş, H. ve Özer, N. (2007). Öğretmen Adaylarının Zaman Yönetimi Becerileri İle Akademik Başarısı Arasındaki İlişkisi. Eğitimde Politika Analizleri ve Stratejik Araşstırmalar Dergisi, 2(1): 44-56.

Durhan, T.A.A (2019). Study on the Effect of Personal Values on Leisure Motivation. Uluslararası Rekreasyon ve Spor Bilimleri Dergisi, 3(1), 25-38.

Erdem, R., Pirinçci, E. ve Dikmetaş, E. (2005). Üniversite Öğrencilerinin Zaman Yönetimi Davranıșları ve $\mathrm{Bu}$ Davranışların Akademik Başarı İle İlişkisi. Manas Üniversitesi Sosyal Bilimler Dergisi, 14, 167-177.

Erdul, G. (2005). Üniversite Öğrencilerinin Zaman Yönetimi Becerileri İle Kayg1 Düzeyleri Arasındaki İlişki. Yüksek Lisans Tezi, Uludağ Üniversitesi Sosyal Bilimler Enstitüsü, Bursa.

Gözel, E. (2009). İlköğretim Okulu Öğretmenlerinin Zaman Yönetimi Hakkındaki Görüşleri. Yüksek Lisans Tezi, Afyon Kocatepe Üniversitesi Sosyal Bilimler Enstitüsü, Afyonkarahisar.

Gümüş, H. ve Özgül, S.A. (2017). Development of scales for barriers to participation and preference factors in theuse of recreation area. Rekreasyon alanı kullanımına ilişkin katılım engelleri ve tercih etkenleri ölçeklerinin geliştirilmesi. Journal of Human Sciences, 14(1), 865-882.

Gümüs, H., Ayna, Ç. ve Yıldırım, İ. (2018). Reviewingattitudes of women towards leisure activities in terms of different variables. Turkish Journal of Sport and Exercise, 20(3), 224-229.

Gürbüz, M. ve Aydın, A.H. (2012). Zaman Kavramı ve Yönetimi. Kahramanmaraş Sütçü İmam Üniversitesi Sosyal Bilimler Dergisi, 1-20.

Güven, M. ve Yeşil, S. (2011). İşletmelerde Zaman Yönetimi (Editör: İ. Bakan), 2. Bask1, Çağdaş Yönetim Yaklaşımları İlkeler, Kavramlar ve Yaklaşımlar. İstanbul: Beta Basım A.Ş.

İşcan, S. (2008). Pamukkale Üniversitesi Öğrencilerinin Zaman Yönetimi Becerilerinin Akademik Başarıları 
Üzerindeki Etkisi. Yayınlanmamış Yüksek Lisans Tezi, Pamukkale Üniversitesi Eğitim Bilimleri Enstitüsü, Denizli.

Karadağ, K. (2013). Zaman Yönetimi ve Yöneticiler. İdarecinin Sesi Dergisi, 99103.

Karaoğlu, B. (2015). Erciyes Üniversitesi Beden Eğitimi Spor Yüksekokulu Öğrencilerinin Zaman Yönetimi Davranışlarının Farklı Değişkenler Açısından İncelenmesi. Yüksek Lisans Tezi, Erciyes Üniversitesi Sağlık Bilimleri Enstitüsü, Kayseri.

Köktaş, Ş. ve Köktaş, V. (2007). Etkili Sınıf Yönetimi, Adana: Çeskod Yayınları.

Macan, T.H.,Shahani C., Dipboye R.L. and Phillips A.P. (1990). "College Students' Time Management: Correlations With Academic Performance And Stress". Journal of Educational Psychology, 82(4), 760-768.

Misra, R. ve Mckean, M. (2000). Collage students' Academic Stress and İts Relation to Their Anxiety, Time Management and Leisure Satisfaction. American Journal of Health Studies, 16(1), 41-51.

Mpofu, E.,D'Amico, M. and Cleghom, A. (1996). Time Management Practices in an AfrieanCulture, Correlates with College Academic Grades. Canadian Journal of Behaviaural Science, 1-13.

Nelson, D.B. and Nelson, K.W. (2003). Emotional Intelligence Skills: Significant Factors in Freshmen Achievement and Retention. Paper presented at the American Counselling Association Conference, Anaheim, CA.

Sugötüren, M., Ballı, Ö.M. ve Gökçe, H. (2011). Spor Bilimleri ve Teknolojisi Yüksekokulunda Öğrenim Gören Öğrencilerin Zaman Yönetimi Davranışları. Spormetre Beden Eğitimi ve Spor Bilimleri Dergisi, 9(3), 91-96.

Tektaş, M. ve Tektaş, N. (2010). Meslek Yüksekokulu Öğrencilerinin Zaman Yönetimi ve Akademik Başarıları Arasındaki İlişki. Selçuk Üniversitesi Sosyal Bilimler Enstitüsü Dergisi, (23), 221-229.
Trueman, M. and Hartley, J.A. (1996). Comparison Between the Time-Management Skills and Academic Performance of Mature and Traditional-Entry University Students. Higher Education, 32(2), 199-215.

Uğur, A. (2000). Çalışma Hayatında Zaman Yönetimi. MPM Kalkınmada Anahtar Verimlilik Dergisi, 18-22.

Uyar, Y. ve Sunay, H. (2009). Üniversite Spor Yöneticiliği Eğitiminin Ankara İli Spor Kamuoyunca Algilanma Düzeyleri Üzerine Bir Araştırma. Spormetre Beden Eğitimi ve Spor Bilimleri Dergisi, 7(4), 141-149.

Yaşar, O. M. ve Sunay, H. (2018). Futbol antrenörlerinin iş doyumlarının ve örgütsel bağlılıklarının incelenmesi. Journal of Human Sciences, 15(2), 952-969.

Yılmaz, M., Sertbaş, K. ve Gumus, H. (2019). Gönüllülerin Faaliyetlere Katılım Nedenleri ve Motivasyonel Faktörlerin Analizi: Gençlik Merkezleri Örneği. Beden Eğitimi ve Spor Bilimleri Dergisi, 21(3), 117-127.

Yılmaz, İ., Yoncalık, O. ve Bektaş, F. (2010). Zaman Yönetimi Davranışı İle Akademik Başarı Arasındaki İlişki. E-Journal of New World Sciences Academy, 5(3): 187-194. 